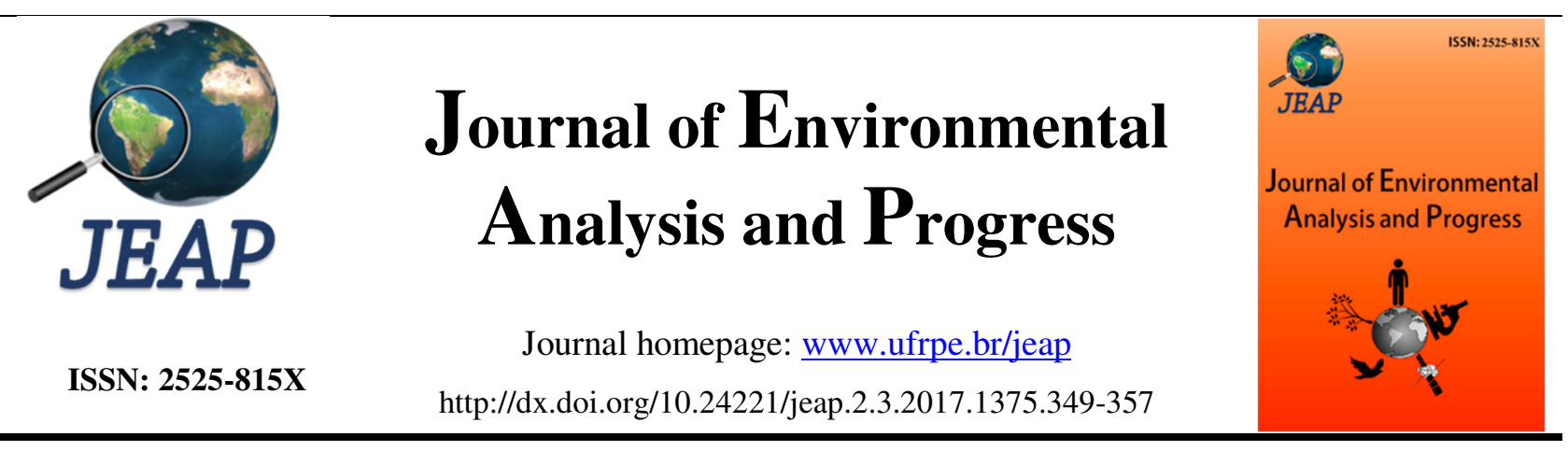

\title{
Caracterização farmacobotânica de Bidens pilosa $\mathbf{L}$.
}

\section{Pharmacobotanical characterization of Bidens pilosa $\mathbf{L}$.}

\author{
Rafaela Damasceno Sáa , Felipe Ribeiro da Silva ${ }^{\mathrm{a}}$, Karina Perrelli Randau ${ }^{\mathrm{a}}$ \\ ${ }^{\text {a }}$ Universidade Federal de Pernambuco-UFPE, Laboratório de Farmacognosia, Departamento de Ciências Farmacêuticas. \\ Av. Prof. Arthur de Sá, S/N, Cidade Universitária, Recife-PE, Brasil. CEP: 50740-521. E-mail: krandau@ @otmail.com
}

\begin{tabular}{l}
\hline A R T I C L E I N F O \\
\hline Recebido 08 Jun 2017 \\
Aceito 08 Jul 2017 \\
Publicado 31 Jul 2017
\end{tabular}

\begin{abstract}
A B S T R A C T
Bidens pilosa L., popularly known as "picão" or "picão-preto", is an herb widely used in Brazilian popular medicine. It is indicated as anti-inflammatory, depurative, diuretic, for the treatment of diabetes, hepatitis and malaria. To contribute to the knowledge about medicinal plants of interest to the Brazilian Unified Health System, this study aims to perform the anatomical and histochemical characterization of $B$. pilosa. Cross-sections were obtained, by hand, for analysis under light microscopy of root, stem, petiole and leaf blade; for the leaf blade were also performed paradermic sections, scanning electron microscopy analysis, maceration and histochemistry. The main characters useful in identifying the species were: secretory structures in all organs analyzed; tector and glandular trichomes on the stem, petiole and leaf blade; sclerenchyma fibers in the phloem of root and stem; anomocytic and anisocytic stomata on the leaf blade. Through histochemistry, it was evidenced the presence of phenolic compounds, lipophilic compounds, lignin and starch. The data presented are useful for the quality control of the species.
\end{abstract}

Keywords: Anatomy, Asteraceae, histoquímica, picão-preto.

\begin{abstract}
R E S U M O
Bidens pilosa L., popularmente conhecida como picão ou picão-preto, é uma erva muito utilizada na medicina popular brasileira. É indicada como anti-inflamatória, depurativa, diurética, para o tratamento de diabetes, hepatite e malária. No intuito de contribuir com o conhecimento sobre as plantas medicinais de interesse ao Sistema Único de Saúde do Brasil, este estudo tem como objetivo realizar a caracterização anatômica e histoquímica de B. pilosa. Secções transversais foram obtidas, a mão livre, para análise em microscopia óptica de raiz, caule, pecíolo e lâmina foliar; para a lâmina foliar também foram realizadas secções paradérmicas, análise em microscopia eletrônica de varredura, maceração e histoquímica. Os principais caracteres úteis na identificação da espécie foram: estruturas secretoras em todos os órgãos analisados; tricomas tectores e glandulares no caule, pecíolo e lâmina foliar; fibras esclerenquimáticas no floema de raiz e caule; estômatos anomocíticos e anisocíticos na lâmina foliar. Através da histoquímica evidenciou-se na lâmina foliar a presença de compostos fenólicos, compostos lipofílicos, lignina e amido. Os dados apresentados são úteis para o controle de qualidade da espécie.

Palavras-Chave: Anatomia, Asteraceae, histoquímica, picão-preto.
\end{abstract}

\section{Introdução}

A família Asteraceae possui cerca de 25.000 espécies, reunidas em 1.500 gêneros. Está distribuída em todo o mundo e muitos de seus representantes são plantas invasoras, dentre elas
Bidens pilosa L. (Souza \& Lorenzi, 2012). Esta é uma herbácea anual, ereta, de 40-120 cm de altura, com odor característico (Lorenzi, 2008). Nativa da América Tropical, possui ampla distribuição, onde no Brasil é encontrada praticamente em todo o 
território (Mondin, Nakajima \& Bringel Jr., 2015) e, de acordo com Santos \& Cury (2011), é uma das mais importantes plantas daninhas em culturas anuais e perenes na região Centro-Sul do país.

Conhecida popularmente como picão ou picão-preto (Gilbert, Alves \& Favoret, 2013), B. pilosa tem sido bastante utilizada por diversas comunidades no Brasil e possui várias indicações terapêuticas, dentre elas como anti-inflamatória (Borges et al., 2013), depurativa e diurética, para o tratamento de diabetes e hepatite (Cordeiro \& Félix, 2014) e para malária (Botsaris, 2007). Todas as partes da planta são usadas na medicina popular, mas principalmente as folhas (Gilbert, Alves \& Favoret, 2013).

De acordo com Bartolome, Villaseñor \& Yang (2013), a diversidade de atividades reportadas para a espécie reflete sua complexidade fitoquímica. Ainda segundo os autores, 201 compostos haviam sido identificados na planta até 2013, incluindo compostos alifáticos, flavonoides, terpenos, fenilpropanoides, aromáticos, porfirinas, dentre outros. Os flavonoides e os poliacetilenos predominam (Silva et al., 2011; Negri, 2015) e as atividades farmacológicas descritas para a planta estão geralmente associadas a presença desses grupos de metabólitos (Cortés-Rojas et al., 2013).

Estudos com os extratos, frações e componentes isolados da planta demonstram atividades antitumoral (Sundararajan et al., 2006; Kumari et al., 2009), anti-inflamatória e analgésica (Fotso et al., 2014), antidiabética (Yang, 2014), hepatoprotetora (Yuan et al., 2008; Suzigan et al., 2009), antioxidante (Chiang et al., 2004; Deba et al., 2007), antimalária, antibacteriana e antifúngica (Deba et al., 2007; Kumari et al., 2009; Tobinaga et al., 2009). Por isso, B. pilosa é uma das 71 espécies vegetais presente na Relação Nacional de Plantas Medicinais de Interesse ao Sistema Único de Saúde que possuem potencial para o desenvolvimento de fitoterápicos (Brasil, 2009).

Nesse sentido, além de estudos fitoquímicos e farmacológicos, é necessário também a realização de estudos que visem a padronização farmacobotânica da espécie. Assim, o objetivo desse estudo foi realizar a caracterização anatômica e histoquímica de B. pilosa, agregando técnicas de microscopia óptica e eletrônica de varredura.

\section{Material e Métodos}

O material vegetal foi coletado em julho de 2015 no campus da Universidade Federal de Pernambuco, situado em Recife, Pernambuco, Brasil. Uma exsicata foi depositada no herbário Dárdano de Andrade Lima, do Instituto
Agronômico de Pernambuco (IPA), sob o número de tombamento 90173.

Para a caracterização anatômica através de microscopia óptica (MO) vários espécimens adultos foram fixados em FAA50 (formaldeído, ácido acético e álcool etílico 50\%; 1:1:18 v/v) (Johansen, 1940). Foram utilizadas raízes principais, caule e folhas situadas entre o terceiro e o quinto nó. Secções transversais foram realizadas na zona de crescimento secundário da raiz, no caule situado entre o terceiro e o quinto nó e na região mediana de pecíolo e lâmina foliar à mão livre, usando lâminas de aço e medula do pecíolo de embaúba (Cecropia sp.) como material de suporte. Para a lâmina foliar também foram realizadas secções paradérmicas nas faces adaxial e abaxial. Em seguida, todas as secções foram submetidas a uma solução de hipoclorito de sódio $(50 \%)$ para processo de descoloração (Kraus \& Arduin, 1997) e lavadas em água destilada. As secções transversais foram coradas segundo técnica descrita por Bukatsch (1972), com safranina e azul de Astra e as secções paradérmicas foram coradas com azul de metileno (Krauter, 1985). Posteriormente, todas as secções foram montadas em lâminas semipermanentes, seguindo procedimentos usuais em anatomia vegetal (Johansen, 1940; Sass, 1951).

Fragmentos de folhas foram macerados com a mistura de ácido nítrico $10 \%$ e ácido crômico $10 \%$ (1:1), de acordo com o método de Jeffrey (Johansen, 1940).

Para a caracterização anatômica através de microscopia eletrônica de varredura (MEV) amostras de lâminas foliares foram fixadas em solução contendo glutaraldeído $2,5 \%$ e tampão cacodilato $0,1 \mathrm{M}$ e pós-fixadas em solução de ósmio $2 \%$ e tampão cacodilato 0,1 M. Após desidratação em série etílica, o material foi submetido à secagem no ponto crítico (CPD 030 BAL-TEC). Em seguida, as amostras foram montadas em stubbs, metalizadas com ouro (Haddad et al., 1998) e analisadas em microscópio eletrônico de varredura (QUANTA 200 FEG) no Centro de Tecnologias Estratégicas do Nordeste (CETENE) em Recife.

A caracterização histoquímica foi realizada em secções transversais de lâminas foliares frescas, obtidas à mão livre, usando lâminas de aço e medula do pecíolo de embaúba como material de suporte. Os seguintes reagentes foram utilizados para indicar a presença das substâncias: dicromato de potássio (10\%) para compostos fenólicos (Gabe, 1968); vanilina clorídrica para taninos (Mace \& Howell, 1974); tricloreto de antimônio para triterpenos e esteroides (Mace, Bell \& Stipanovic, 1974); Dragendorff para alcaloides (Brasil, 2010); 
Sudan III para compostos lipofílicos (Sass, 1951); floroglucinol para lignina (Johansen, 1940); Lugol para amido (Johansen, 1940) e ácido clorídrico (10\%) para estabelecer a natureza dos cristais (Jensen, 1962). Controles foram realizados em paralelo aos testes histoquímicos e lâminas semipermanentes foram preparadas contendo as secções transversais (Johansen, 1940; Sass, 1951).

A análise das lâminas histológicas preparadas para a caracterização anatômica através de MO e para a histoquímica foram conduzidas em imagens obtidas a partir de microscópio óptico (Alltion) com auxílio do software Toup View Image.

\section{Resultados}

Em secção transversal, a raiz de Bidens pilosa possui contorno circular (Figura 1A). Observa-se o desenvolvimento de crescimento secundário com a presença de periderme (Figura 1B). A região cortical é formada por cerca de 3 a 5 camadas de parênquima. Nela são encontrados ductos secretores (Figura 1BC). A endoderme é unisseriada e possui estrias de Caspary.
O xilema ocupa a região central da raiz e apresenta raios parenquimáticos (Figura $1 \mathrm{AB}$ ). $\mathrm{O}$ floema circunda o xilema, arranjado em poucas camadas de células (Figura 1AB). Grupos de fibras pericíclicas são encontradas no floema Figura 1D).

$\mathrm{O}$ caule, em secção transversal, exibe contorno circular (Figura 1E). A epiderme é unisseriada, recoberta por uma fina camada de cutícula e possui estômatos (Figura 1E). Observase a presença de tricomas tectores e glandulares (Figura 1F). Ambos são unisseriados e multicelulares, porém, os tricomas tectores possuem base multicelular.

A região cortical do caule é formada por 1 a 2 camadas de colênquima e por cerca de 4 a 6 camadas de parênquima (Figura 1E). Assim como foi encontrado na raiz, ductos secretores também são visualizados na região cortical do caule. Entretanto, no caule eles também estão presentes na região medular, situados próximos aos feixes vasculares (Figura 1E). Os feixes vasculares são colaterais (Figura 1E) e fibras pericíclicas estão situadas junto ao floema (Figura 1E).
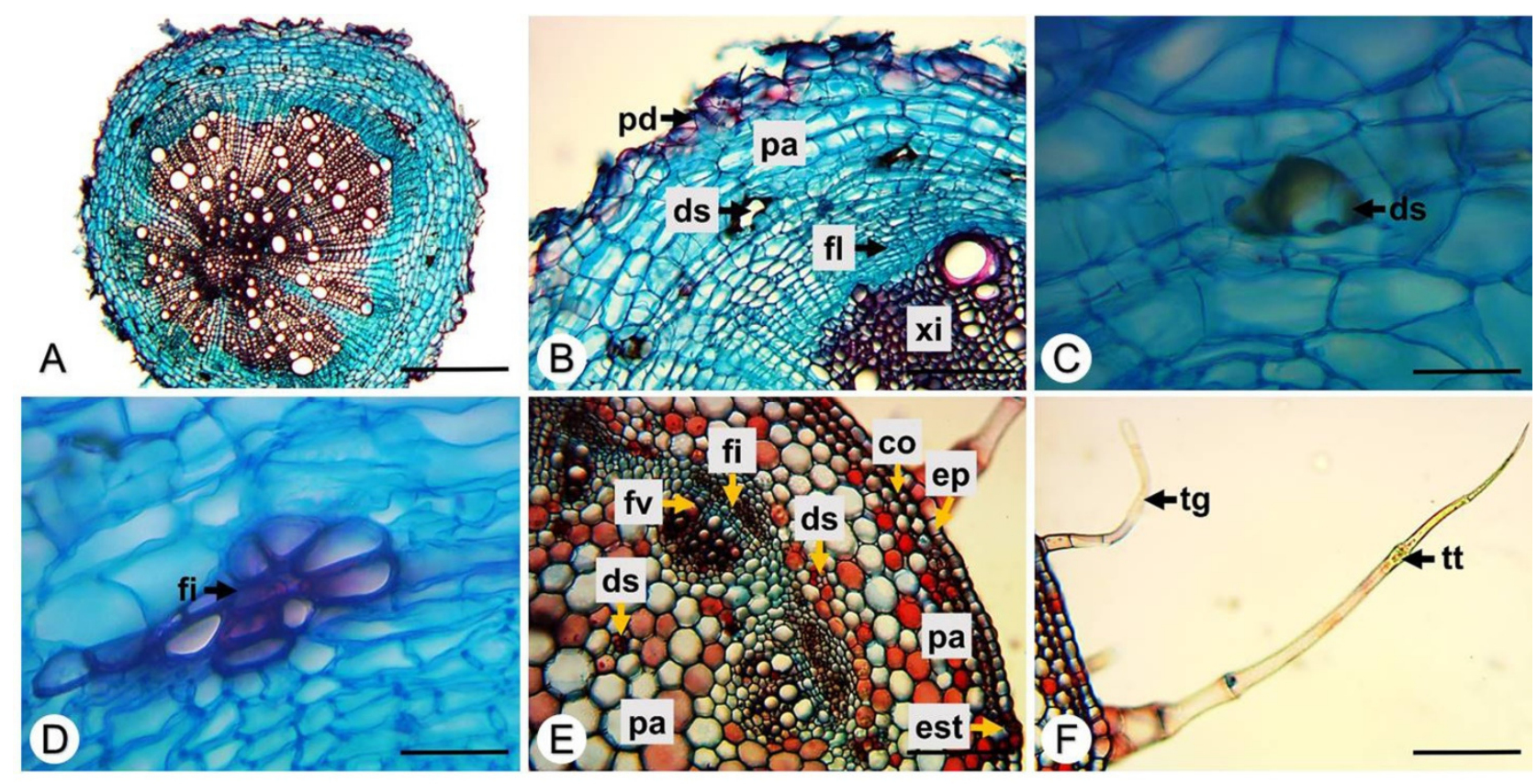

Figura 1. Secções transversais da raiz e do caule de Bidens pilosa L. A e B. Aspecto geral da raiz; C. Detalhes de ducto secretor na raiz; D. Fibras pericíclicas no floema da raiz; E. Aspecto geral do caule; F. Tricomas presentes no caule. Abreviaturas: $\mathrm{co}=$ colênquima; ds $=$ ducto secretor; ep $=$ epiderme; est $=$ estômato; fi $=$ fibra; $\mathrm{fl}=$ floema $\mathrm{fv}=$ feixe vascular; $\mathrm{pa}=$ parênquima; $\mathrm{pd}=$ periderme; $\mathrm{tg}=$ tricoma glandular; $\mathrm{tt}=$ tricoma tector; $\mathrm{xi}=$ xilema. Barras: $\mathrm{A}=500 \mu \mathrm{m} ; \mathrm{B}, \mathrm{E}$ e $\mathrm{F}=200 \mu \mathrm{m}$; $\mathrm{C}$ e $\mathrm{D}=50 \mu \mathrm{m}$.

O pecíolo, em secção transversal, apresenta formato côncavo-convexo, com duas regiões mais proeminentes na face adaxial (Figura 2A). Possui epiderme composta por uma única camada de células, recoberta por cutícula fina e apresenta estômatos ao mesmo nível das demais células epidérmicas (Figura 2AD).

Os tipos de tricomas presentes no pecíolo são os mesmos tipos encontrados no caule (Figura $2 \mathrm{ABC}$ ). Adjacente à epiderme observa-se de uma a duas camadas de colênquima, sendo mais 
desenvolvido nas regiões proeminentes na face adaxial (Figura 2AD). Os feixes vasculares são colaterais. Eles estão dispostos na forma de um arco, sendo 3 feixes maiores na região central e feixes menores situados próximos à face adaxial (Figura 2A). Ductos secretores são visualizados próximos aos feixes vasculares (Figura 2AE).

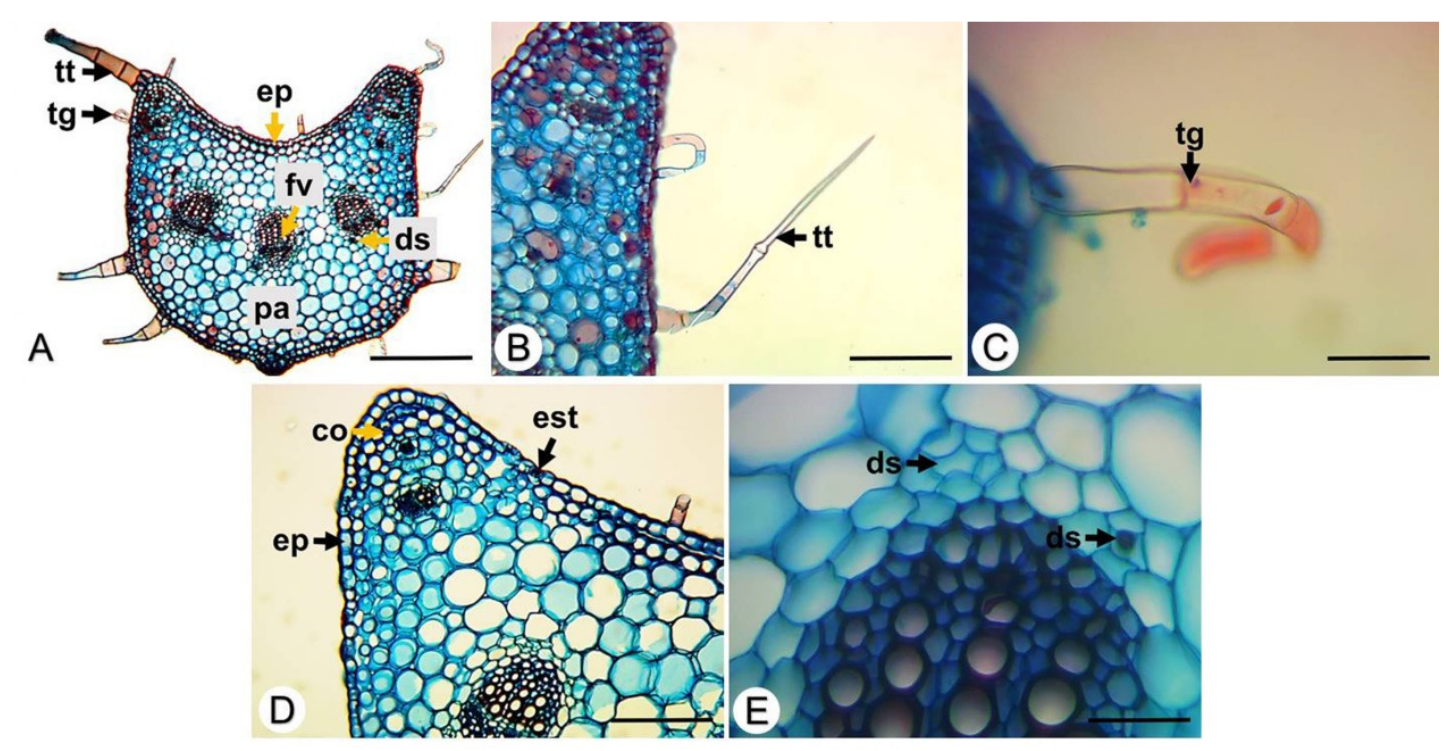

Figura 2. Secções transversais do pecíolo de Bidens pilosa L. A. Aspecto geral; B. Tricoma tector; C. Tricoma glandular; D. Detalhe da epiderme com estômato; E. Ductos secretores próximos ao feixe vascular. Abreviaturas: $\mathrm{co}=$ colênquima; $\mathrm{ds}=$ ducto secretor; $\mathrm{ep}=$ epiderme; est $=$ estômato; $\mathrm{fv}=$ feixe vascular; $\mathrm{pa}=$ parênquima; $\mathrm{tg}=$ tricoma glandular; $\mathrm{tt}=$ tricoma tector. Barras: $\mathrm{A}=500 \mu \mathrm{m} ; \mathrm{B}=200 \mu \mathrm{m} ; \mathrm{C}, \mathrm{D}$ e $\mathrm{E}=50 \mu \mathrm{m}$.

A lâmina foliar, em vista frontal sob MO, apresenta estômatos anomocíticos e anisocíticos, sendo o primeiro mais abundante (Figura $3 \mathrm{ABC}$ ). As células epidérmicas possuem paredes de contorno sinuoso nas duas faces (Figura $3 \mathrm{ABC}$ ). Após observação da lâmina foliar em MEV podese verificar que as células epidérmicas, em ambas as faces, são recobertas por cutícula levemente estriada (Figura 3EF).

Tanto em MO quanto em MEV pode ser verificada a presença de tricomas tectores e glandulares (Figura $3 \mathrm{ABCDGH}$ ). Ambos foram verificados nas duas faces da lâmina foliar de $B$. pilosa. Os tricomas tectores são mais frequentes do que os glandulares.
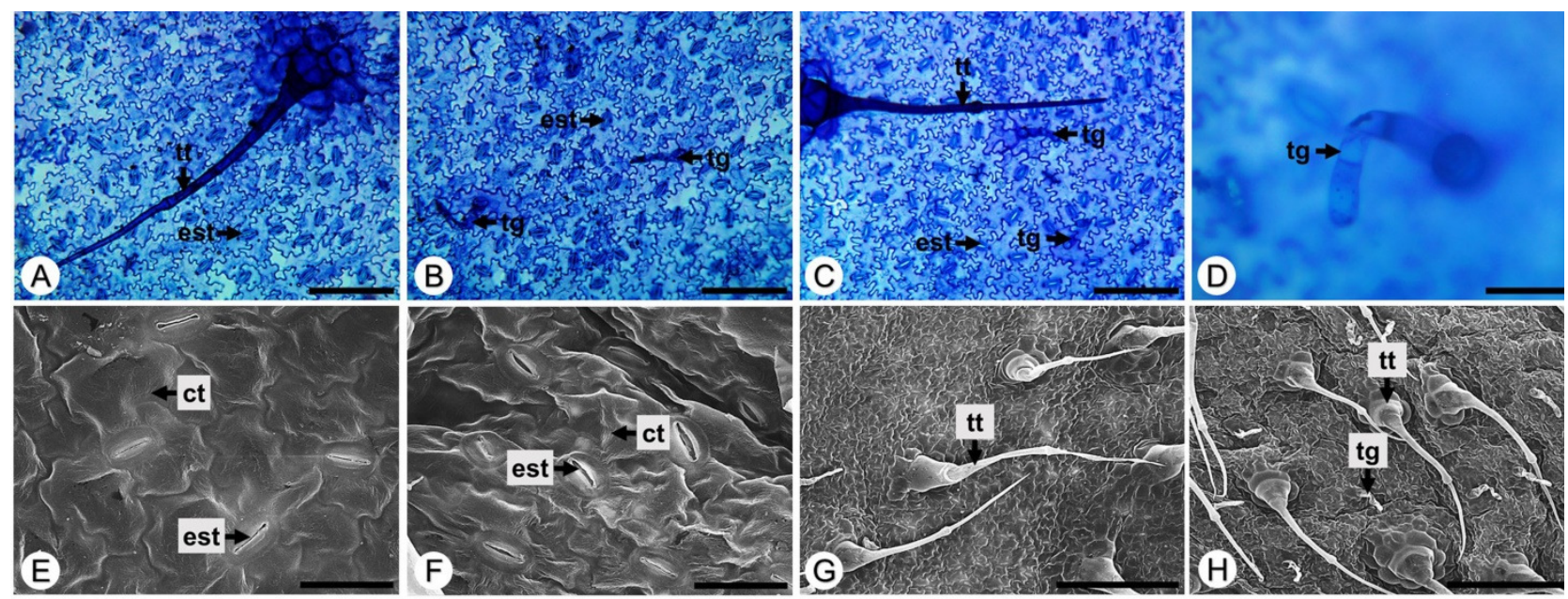

Figura 3. Secções paradérmicas da lâmina foliar de Bidens pilosa L. A, B, E e G. Face adaxial; C, D, F e H. Face abaxial. Abreviaturas: $\mathrm{ct}=$ cutícula; est $=$ estômato; $\operatorname{tg}=$ tricoma glandular; $\operatorname{tr}=$ tricoma tector. Barras: $\mathrm{A}-\mathrm{C}=200 \mu \mathrm{m} ; \mathrm{D}-\mathrm{F}=50 \mu \mathrm{m} ; \mathrm{G}$ e $\mathrm{H}=400 \mu \mathrm{m}$.

A nervura central, em secção transversal, possui formato biconvexo (Figura 4A). A epiderme é composta por uma camada de células arredondadas, recoberta por cutícula delgada. Os tricomas tectores e glandulares também podem ser observados (Figura 4B). Adjacente à epiderme da 
região adaxial da nervura encontra-se uma a duas camadas de colênquima angular (Figura 4A). Os feixes vasculares colaterais, que podem ser até três, estão envolvidos por parênquima na região central da nervura (Figura 4AC). No parênquima também há células contendo grãos de amido (Figura 4B) e, próximo aos feixes vasculares, são observados ductos secretores (Figura 4C).
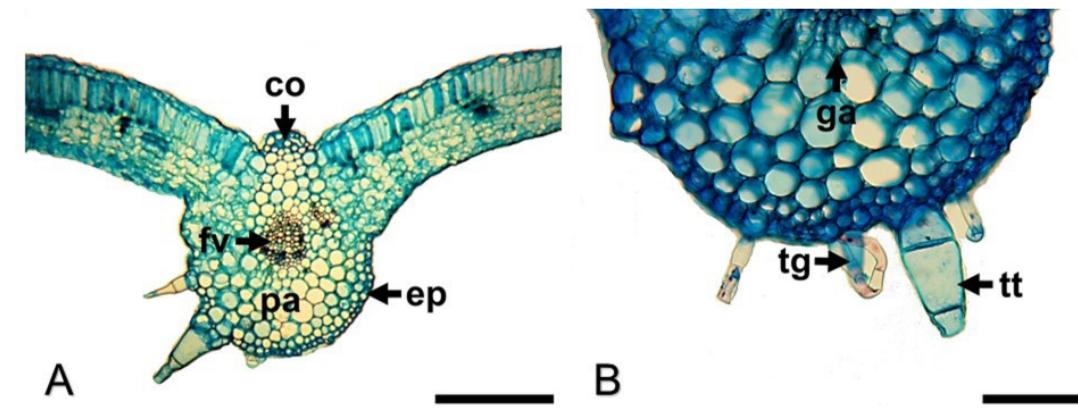

B

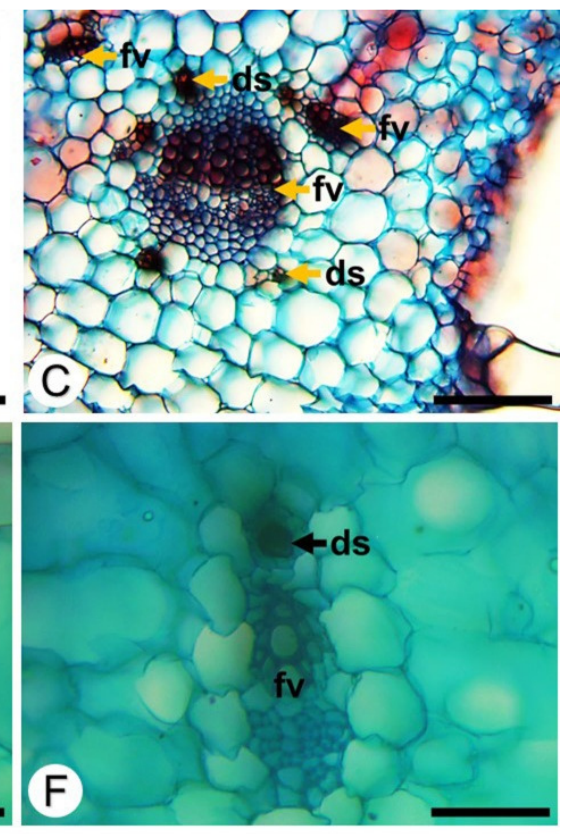

D

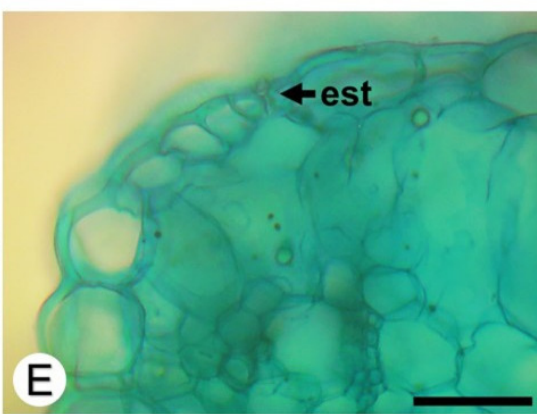

Figura 4. Secções transversais da lâmina foliar de Bidens pilosa L. A-C. Nervura central; D-F. Mesofilo. Abreviaturas: $\mathrm{co}=$ colênquima; $\mathrm{ds}=$ ducto secretor; $\mathrm{ep}=$ epiderme; est $=$ estômato; $\mathrm{fv}=$ feixe vascular; $\mathrm{ga}=$ grãos de amido; $\mathrm{pa}=$ parênquima; $\mathrm{pe}=$ parênquima esponjoso; $\mathrm{pp}=$ parênquima paliçádico; $\mathrm{tg}=$ tricoma glandular; $\mathrm{tt}=$ tricoma tector. Barras: $\mathrm{A}=500 \mu \mathrm{m} ; \mathrm{B}-\mathrm{D}=200 \mu \mathrm{m} ; \mathrm{E}$ e $\mathrm{F}=50 \mu \mathrm{m}$.

Através do corte transversal também é evidenciada a presença de estômatos (Figura 4DE). O mesofilo é constituído de um estrato de parênquima paliçádico e cerca de seis estratos de parênquima esponjoso (Figura 4D). Nervuras secundárias são encontradas em todo o mesofilo, envoltas por bainha parenquimática com ductos próximos a elas, semelhante ao encontrado na nervura central (Figura 4F).
Através da maceração foram evidenciados fragmentos de tecido epidérmico com os estômatos e tricomas (Figura 5A), bem como a observação dos tricomas (Figura 5BD) ou de suas bases isoladas do tecido epidérmico, principalmente as bases do tricomas tectores (Figura 5C), além de elementos de vaso do tipo helicoidal (Figura 5E).

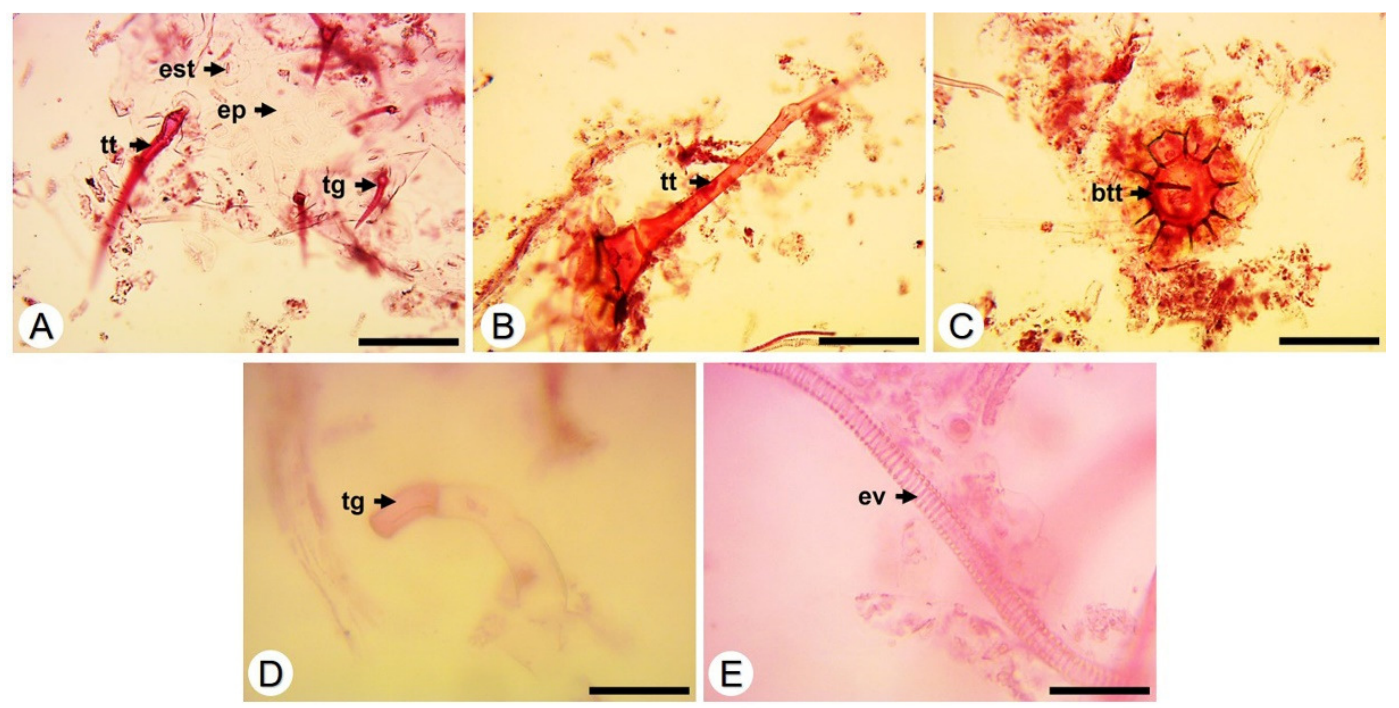

Figura 5. Macerado de folhas de Bidens pilosa L. A. Fragmento de tecido epidérmico com estômatos e tricomas tectores e glandulares; B. Tricoma tector íntegro; C. Base do tricoma tector; D. Tricoma glandular íntegro; E. 
Elemento de vaso do tipo helicoidal. Abreviaturas: $b t t=$ base do tricoma tector; $\mathrm{ep}=$ epiderme; est = estômato; $\mathrm{ev}=$ elemento de vaso; $\mathrm{tg}=$ tricoma glandular; $\mathrm{tt}=$ tricoma tector. Barras: $\mathrm{A}-\mathrm{C}=200 \mu \mathrm{m} ; \mathrm{D}$ e $\mathrm{E}=50 \mu \mathrm{m}$.

A Figura $6 \mathrm{AB}$ mostra a secção transversal da lâmina foliar sem adição de reagente. Compostos fenólicos foram encontrados nas células epidérmicas (Figura 6C), enquanto que compostos lipofílicos foram encontrados na cutícula e em algumas inclusões em células do parênquima paliçádico (Figura 6D). Também foram evidenciados a lignina presente no xilema (Figura 6E) e os grãos de amidono parênquima (Figura 6F). Os testes para taninos, triterpenos e esteroides, alcaloides e cristais foram negativos.
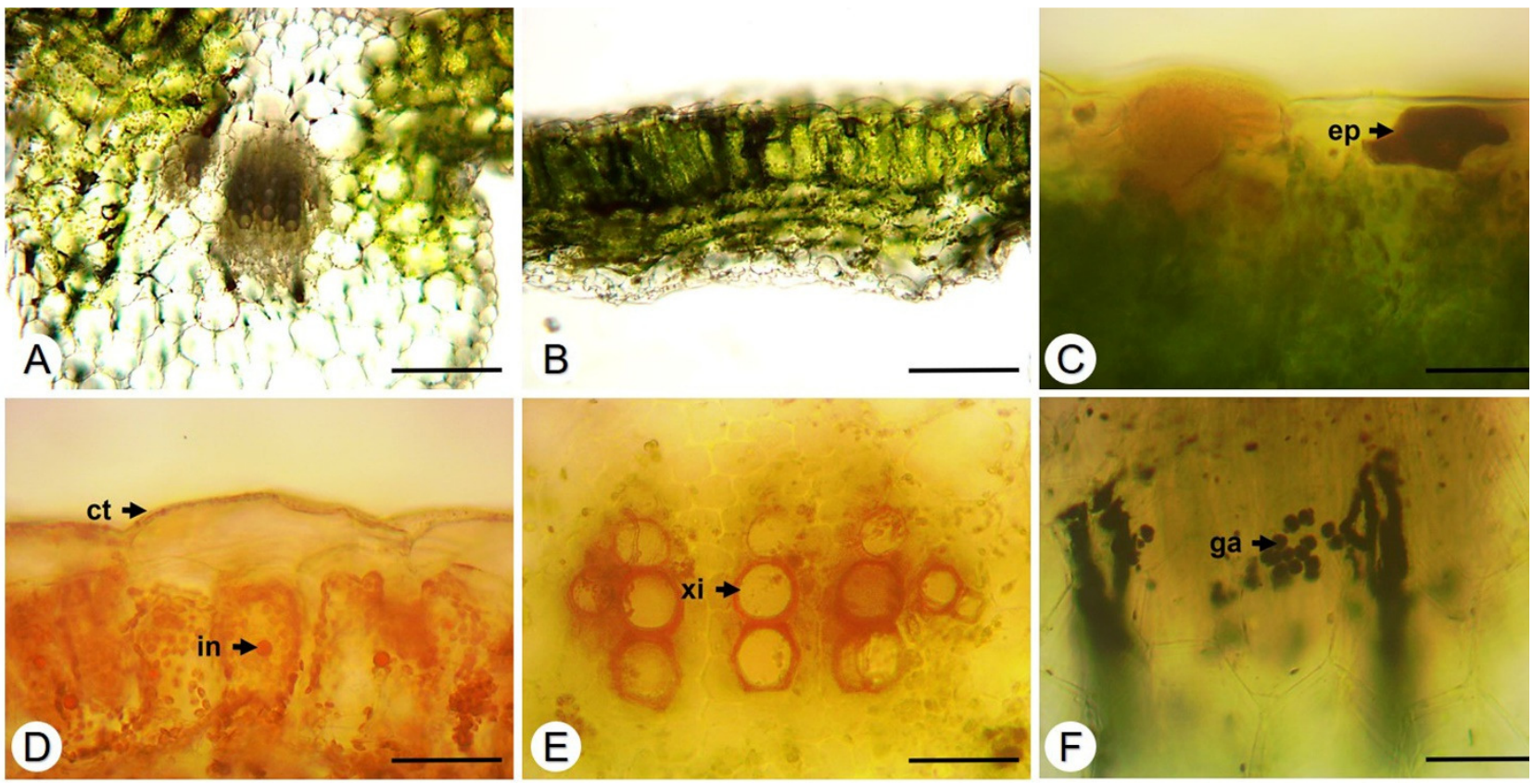

B

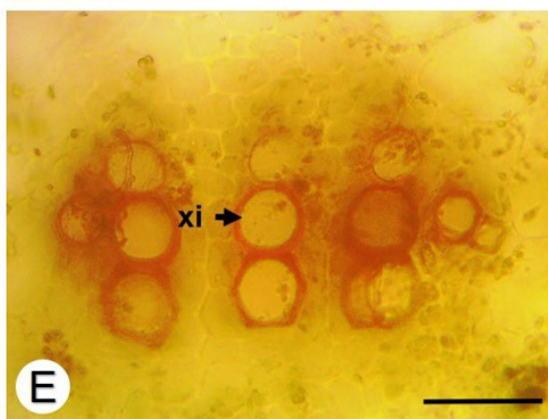

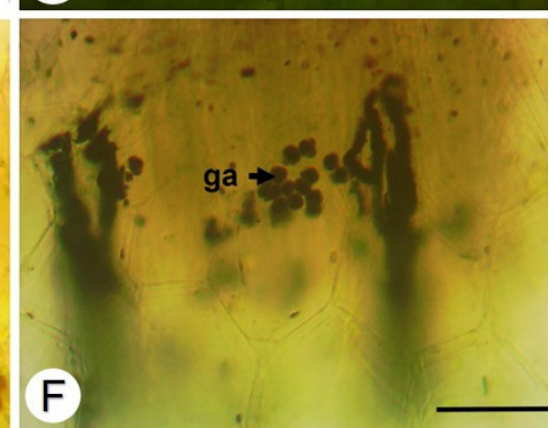

Figura 6. Histoquímica na lâmina foliar de Bidens pilosa L. A e B. Controle; C. Dicromato de potássio (10\%); D. Sudan III; E. Floroglucinol; F. Lugol. Abreviaturas: ct = cutícula; ep = epiderme; ga = grãos de amido; in $=$ inclusão; $x i=$ xilema. Barras: $\mathrm{A}$ e $\mathrm{B}=200 \mu \mathrm{m} ; \mathrm{C}-\mathrm{F}=50 \mu \mathrm{m}$.

\section{Discussão}

$\mathrm{Na}$ família Asteraceae a presença de estruturas secretoras em todos os órgãos da planta é uma característica comum (Metcalfe \&Chalk, 1950) e, segundo Evert (2006), elas são de natureza esquizógena. Duarte \& Estelita (1999), Arroyo et al. (2008) e Colares et al. (2014) também identificaram essas estruturas na região cortical da raiz de B. pilosa. De acordo com Duarte \& Estelita (1999) os ductos apresentam epitélio uniestratificado, com conteúdo denso e núcleo proeminente. Além disso, estes autores realizaram teste com Sudan IV e verificaram que o produto de secreção dos ductos é de natureza lipofílica. Apesar de ser uma característica comum, há espécies de Asteraceae que não apresentam estruturas secretoras na raiz, como é o caso de Ageratum conyzoides (Santos et al., 2016).

Colares et al. (2014) mencionaram que a região medular da raiz de $B$. pilosa é parenquimática, divergindo do que foi encontrado por Duarte \& Estelita (1999), Arroyo et al. (2008) e deste estudo. Outros membros de Asteraceae possuem região medular parenquimática, como
Ageratum conyzoides (Santos et al., 2016), A. houstonianum (Das \& Mukherjee, 2013) e Pluchea sagittalis (Colares et al., 2014).

Duarte \& Estelita (1999) observaram que, em secção transversal, o caule de B. pilosa apresenta formato aproximadamente quadrangular e que o pecíolo apresenta formato plano-convexo, enquanto que no presente estudo foi encontrado um formato circular para o caule e côncavo-convexo para o pecíolo.

No caule, no pecíolo e na lâmina foliar os ductos secretores estão localizados próximos ao floema e ao xilema. Há espécies de Asteraceae em que as estruturas secretoras estão associadas ou próximas exclusivamente ao floema; outras em que as estruturas secretoras estão associadas ou próximas exclusivamente ao xilema e ainda espécies em que as estruturas secretoras estão associadas ou próximas ao floema e ao xilema (Castro, Leitão-Filho \& Monteiro, 1997).

De acordo com Metcalfe \& Chalk (1950), tricomas tectores e glandulares são comuns na família Asteraceae. Ambos foram verificados no caule, pecíolo e nas duas faces da lâmina foliar. 
Essiett \& Archibong (2014) também relataram a presença de tricomas glandulares na espécie, porém, os autores afirmaram sua presença apenas na face abaxial. Outros estudos citaram somente a presença de tricomas tectores (Duarte \& Estelita, 1999; Ferreira et al., 2002; Arroyo et al., 2008; Mabel et al., 2014).

Duarte \& Estelita (1999), Ferreira et al. (2002) e Arroyo et al. (2008) citam apenas a presença de estômatos anomocíticos em ambas as faces da lâmina foliar da espécie. De acordo com Duarte \& Estelita (1999), os estômatos situados na face adaxial, localizados nas das bordas da lâmina foliar, são aquíferos. Os feixes vasculares da nervura central também foram identificados por Duarte \& Estelita (1999) como sendo do tipo colateral, enquanto que Mabel et al. (2014) afirmaram que eles são do tipo anficrival. A literatura não informa sobre a maceração da folha da espécie. Entretanto, Duarte \& Estelita (1999) realizaram a dissociação dos tecidos do caule e da raiz de $B$. pilosa em estufa, com mistura de água oxigenada e ácido acético glacial. Foi verificada a presença de elementos de vaso com ornamentação da parede lateral do tipo anelado, helicoidal ou escalariforme e com pontoações, apresentando placas de perfuração simples e escalariforme.

Com relação aos metabólitos pesquisados neste estudo através da histoquímica, apenas a ausência de triterpenos e esteroides está em desacordo com a literatura (Silva et al., 2011; Bartolome, Villaseñor \& Yang, 2013). Entretanto, essa divergência pode ser explicada pelas diferentes áreas onde a espécie foi coletada para a realização dos estudos. De acordo com GobboNetto \& Lopes (2007), a síntese dos metabólitos secundários é frequentemente influenciada pelas condições ambientais. As pesquisas que identificaram triterpenos e esteroides em B. pilosa foram conduzidas com material vegetal coletado no Egito (Sarg et al., 1991), na Tanzânia (Geissberger \& Séquin, 1999) e em Taiwan (Chang et al., 2000).

\section{Conclusão}

A utilização de diferentes técnicas de microscopia para a análise dos caracteres anatômicos de $B$. pilosa permitiu a confirmação de dados previamente descritos para a espécie, bem como trouxe novas informações, principalmente sobre os tipos de tricomas, estômatos e sobre a maceração. Com a realização dos testes histoquímicos, foram evidenciados os metabólitos produzidos pela lâmina foliar da espécie, com destaque para os compostos fenólicos, que são indicados na literatura como um dos principais grupos farmacologicamente ativos. Os dados encontrados neste estudo fornecem subsídios para o controle de qualidade desta matéria-prima vegetal de grande importância etnomedicinal e farmacológica.

\section{Agradecimentos}

Os autores agradecem ao Centro de Tecnologias Estratégicas do Nordeste-CETENE pela realização das análises em Microscopia Eletrônica de Varredura.

\section{Referências}

ARROYO, J.; BONILLA, P.; ORÉ, R.; RÁEZ, E.; MARIN, M.; VALENCIA, J.; JUSTIL, H.; MARTÍNEZ, J.; PALOMINO, C. 2008. Estudio morfohistológico y efecto quimio protector de las hojas de Bidens pilosa $\mathrm{L}$. sobre el cáncer de colon inducido en ratas. An. Fac. Med., v. 69, n. 2, p. 7783.

BARTOLOME, A. P.; VILLASEÑOR, I. M.; YANG, W. C. 2013. Bidens pilosa L. (Asteraceae): botanical properties, traditional uses, phytochemistry, and pharmacology. J. Evid. Based. Complementary Altern. Med., v. 2013, ID 340215, $51 \mathrm{p}$.

BORGES, C. C.; MATOS, T. F.; MOREIRA, J.; ROSSATO, A. E.; ZANETTE, V. C.; AMARAL, P. A. 2013. Bidens pilosa L. (Asteraceae): traditional use in a community of southern Brazil. Rev. Bras. Pl. Med., v. 15, n. 1, p. 34-40.

BOTSARIS, A. S. 2007. Plants used traditionally to treat malaria in Brazil: the archives of Flora Medicinal. J. Ethnobiol. Ethnomed., v. 1, p. 13-18.

BRASIL. Ministério da Saúde. 2009. Plantas de interesse ao SUS. Disponível em: http://bvsms.saude.gov.br/bvs/sus/pdf/marco/ms_r elacao_plantas_medicinais_sus_0603.pdf. Acesso em: 19 abril, 2017.

BRASIL. 2010. Farmacopeia Brasileira. Agência Nacional de Vigilância Sanitária, Brasília.

BUKATSCH, F. 1972. Bemerkungenzur Doppelfärbung Astrablau-Safranin. Mikrokosmos, v. 61, n. 8 , p. 255.

CASTRO, M. M.; LEITÃO-FILHO, H. F.; MONTEIRO, W. R. 1997. Utilização de estruturas secretoras na identificação dos gêneros de Asteraceae de uma vegetação de cerrado. Rev. Bras. Bot., v. 20, n. 2, p. 163-174.

CHANG, M. H.; WANG, G. J.; KUO, Y. H.; LEE, C. K. 2000. The low polar constituents from Bidens 
pilosa L. var. minor (Blume) Sherff. J. Chin. Chem. Soc., v. 47, p. 1131-1136.

CHIANG, Y. M., CHUANG, D. Y.; WANG, S. Y.; KUO, Y. H.; TSAI, P. W.; SHYUR, L. F. 2004. Metabolite profiling and chemo preventive bioactivity of plant extracts from Bidens pilosa. J. Ethnopharmacol., v. 95, p. 409-419.

COLARES, M. N.; HERNÁNDEZ, M. P.; NOVOA, M. C.; PERROTTA, V. G.; AUGUET, S.; ARAMBARRI, A.; M. 2014. Anatomía comparada de raíces medicinales de hierbas terrestres rioplatenses (Buenos Aires, República Argentina). Dominguezia, v. 30, n. 1, p. 5-17.

CORDEIRO, J. M. P.; FÉLIX, L. P. 2014. Conhecimento botânico medicinal sobre espécies vegetais nativas da caatinga e plantas espontâneas no agreste da Paraíba, Brasil. Rev. Bras. Pl. Med., v. 16, n. 3 , p. 685-692.

CORTÉS-ROJAS, D. F.; CHAGAS-PAULA, D. A.; COSTA, F. B.; SOUZA, C. R. F.; OLIVEIRA, W. P. 2013. Bioactive compounds in Bidens pilosa L. populations: a key step in the standardization of phytopharmaceutical preparations. Braz. J. Pharmacogn., v. 23, p. 28-35.

DAS, K. S.; MUKHERJEE, S. K. R. 2013. Comparative morphological, anatomical and palynological observation in Ageratum conyzoides and Ageratum houstonianum of the family Compositae. Int. J. Pharm. Res. Bio Sci., v. 2, p. 48-62.

DEBA, F., XUAN, T. D.; YASUDA, M.; TAWATA, S. 2007. Herbicidal and fungicidal activities and identification of potential phytotoxins from Bidens pilosa L. var. radiata Scherff. Weed Biol. Manag., v. 7, p. 77-83.

DUARTE, M. R.; ESTELITA, M. E. 1999. Caracteres anatômicos de Bidens pilosa $\mathrm{L}$. Asteraceae. Hoehnea, v. 26, n. 1, p. 15-27.

ESSIETT, U. A.; ARCHIBONG, I. A. 2014.The taxonomic significance of certain anatomical variation in four genera of Asteraceae. Bull. Env. Pharmacol. Life Sci., v. 3, n. 5, p. 150-163.

EVERT, R. F. 2006. Esau's plant anatomy: meristems, cells, and tissues of the plant body: their structure, function, and development. John Wiley $\&$ Sons, New Jersey, Third Edition.
FERREIRA, E. A.; PROCÓPIO, S. O.; SILVA, E. A. M.; SILVA, A. A.; RUFINO, R. J. N. 2002. Estudos anatômicos de folhas de espécies de plantas daninhas. II - Bidens pilosa, Emilia sonchifolia, Ageratum conyzoides e Sonchus asper. Planta Daninha, v. 20, n. 3, p. 327-335.

FOTSO, A. F.; LONGO, F.; DJOMENI, P. D. D.; KOUAM, S. F.; SPITELLER, M.; DONGMO, A. B.; SAVINEAU, J. P. 2014. Analgesic and antiinflammatory activities of the ethyl acetate fraction of Bidens pilosa (Asteraceae). Inflammopharmacol., v. 22, p. 105-114.

GABE, M. 1968. Techniques histologiques. Masson \& Cie, Paris.

GEISSBERGER, P.; SÉQUIN, U. 1999. Constituents of Bidens pilosa L.: Do the components found so far explain the use of this plant in traditional medicine? Acta Tropica, v. 48, p. 251-261.

GILBERT, B.; ALVES, L. F.; FAVORETO, R. 2013. Bidens pilosa L. Asteraceae (Compositae; subfamília Heliantheae). Rev. Fitos, v. 8, n. 1, p. 172.

GOBBO-NETO, L.; LOPES, N. P. 2007. Plantas medicinais: fatores de influência no conteúdo de metabólitos secundários. Quím. Nova, v. 30, v. 2, p. 374-381.

HADDAD, A.; SESSO, A.; ATTIAS, M.; FARINA, M.; MEIRELLES, M. N.; SILVEIRA, M.; BENCHIMOL, M.; SOARES, M. J.; BARTH, O. M.; PADRÓN, T. S.; SOUZA, W. 1998. Técnicas básicas de microscopia eletrônica aplicadas às Ciências Biológicas. Sociedade Brasileira de Microscopia Eletrônica, Rio de Janeiro.

JENSEN, W. A. 1962. Botanical histochemistry, principles and practice. W. H. Freeman, San Francisco.

JOHANSEN, D. A. 1940. Plant Microtechnique. Mc Graw Hill, New York.

KRAUS, J. E; ARDUIN, M. 1997. Manual básico de métodos em morfologia vegetal. EDUR, Rio de Janeiro.

KRAUTER, D. 1985. Erfahrungenmit Etzolds FSA-Färbungfürpflanzenschnitte. Mikrokosmos, v. 74, p. 231-233. 
KUMARI, P.; MISRA, K.; SISODIA, B. S.; FARIDI, U.; SRIVASTAVA, S.; LUQMAN, S.; DAROKAR, M. P.; NEGI, A. S.; GUPTA, M. M.; SINGH, S. C.; KUMAR, J. K. 2009. A promising anticancer and antimalarial component from the leaves of Bidens pilosa. Planta Med., v. 75, p. 5961.

LORENZI, H. 2008. Plantas daninhas do Brasil: terrestres, aquáticas, parasitas e tóxicas. Editora Instituto Plantarum, Nova Odessa, Fourth Edition.

MABEL, A. F.; JOHNSON, A. A.; OLUFEMI, O. O.; AYOMIPO, A. A. T. 2014. Foliar anatomy of some species of Asteraceae in South Western Nigeria. Afr. J. Plant Sci., v. 8, p. 426-440.

MACE, M. E.; BELL, A. A.; STIPANOVIC, R. D. 1974. Histochemistry and isolation of gossypol and related terpenoids in root of cotton seedlings. Phytophatol., v. 64, p. 1297-1302.

MACE, M. Z.; HOWELL, C. R. 1974. Histochemistry and identification of condensed tannin precursors in roots of cotton seedlings. Can. J. Bot., v. 52, p. 2423-2426.

METCALFE, C. R.; CHALK, K. L. 1950. Anatomy of the dicotyledons: leaves, stem, and wood in relation to taxonomy with notes on economic uses. Clarendon, Oxford.

MONDIN, C. A., NAKAJIMA, J. N.; BRINGEL JR., J. B. A. 2015. Bidens in Lista de Espécies da Flora do Brasil. Jardim Botânico do Rio de Janeiro. Disponível em: http://floradobrasil.jbrj.gov.br/jabot/floradobrasil/ FB103749. Acesso em: 19 abril, 2017.

NEGRI, R. 2015. Polyacetylenes from terrestrial plants and fungi: recent phytochemical and biological advances. Fitoterapia, v. 106, p. 92-109.

SANTOS, J. B.; CURY, J. P. 2011. Picão-preto: uma planta daninha especial em solos tropicais. Planta Daninha, v. 29, p. 1159-1171.

SANTOS, R. F.; NUNES, B. M.; SÁ, R. D.; SOARES, L. A. L.; RANDAU, K. P. 2016. Morpho-anatomical study of Ageratum conyzoides. Braz. J. Pharmacogn., v. 26, p. 679-687.
SARG, T.M.; ATEYA, A.M.; FARRAG, N.M.; ABBAS, F.A. 1991. Constituents and biological activity of Bidens pilosa L. grown in Egypt. Acta Pharm. Hung., v. 61, p. 317-323.

SASS, J. E. 1951. Botanical microtechnique. The Iowa State College Press, Ames, Second Edition.

SILVA, F. L., FISCHER, D. C. H.; TAVARES, J. F.; SILVA, M. S.; ATHAYDE-FILHO, P. F.; BARBOSA-FILHO, J. M. 2011. Compilation of secondary metabolites from Bidens pilosa $\mathrm{L}$. Molecules, v. 16, p. 1070-1102.

SOUZA, V. C.; LORENZI, H. 2012. Botânica sistemática-guia ilustrado para identificação das famílias de fanerógamas nativas e exóticas no Brasil, baseado em APG III. Instituto Plantarum, Nova Odessa.

SUNDARARAJAN, P.; DEY, A.; SMITH, A.; DOSS, A. G.; RAJAPPAN, M.; NATARAJAN, S. 2006. Studies of anticancer and antipyretic activity of Bidens pilosa whole plant. Afr. Health Sci., v. 6, p. 27-30.

SUZIGAN, M. I.; BATTOCHIO, A. P. R.; COELHO, K. L. R.; COELHO, C. A. R. 2009. An acqueous extract of Bidens pilosa L. protects liver from cholestatic disease. Experimental study in young rats. Acta Cir. Bras., v. 24, n. 5, p. 347-352.

TOBINAGA, S.; SHARMA, M. K.; AALBERSBERG, W. G. L.; WATANABE, K.; IGUCHI, K.; NARUI, K.; SASATSU, M.; WAKI, S. 2009. Isolation and identification of a potent antimalarial and antibacterial polyacetylene from Bidens pilosa. Planta Med., v. 75, p. 624-628.

YANG, W. C. 2014. Botanical, pharmacological, phytochemical, and toxicological aspects of the antidiabetic plant Bidens pilosa L. J. Evid. Based. Complementary Altern. Med., v. 2014, ID 698617 , $14 \mathrm{p}$.

YUAN, L. P.; CHEN, F. H.; LING, L.; DOU, P. F.; BO, H.; ZHONG, M. M.; XIA, L. J. 2008. Protective effects of total flavonoids of Bidens pilosa $\mathrm{L}$. (TFB) on animal liver injury and liver fibrosis. J. Ethnopharmacol., v. 116, p. 539-546. 